MEDICO-PSYCHOLOGICAL ASSOCIATION.-IRISH MERTING.

A Quarterly Meeting of the Medico-Psychological Association was held at the Rojal College of Physicians, Dublin, on Thursday, November 29th, 1885. Present, W. H. Gurner, F.R.C.S.I., in the chair, Dr. Ashe, A. Patton, M.B., Dr. Merrick, T. Draper, M.B., J. Moloney, L.K.Q.C.P., E. M. Courtenay, M.B.

Dr. MoLONEY showed some interesting specimens of instruments of restraint formerly in use in Swift's Hospital.

Dr. PATTON read notes of two cases of insanity connected with injury of the recto-vesical septum during parturition. In one recovery resulted after severe hæmorrhage; in the other, after a prolonged condition of melancholia, the case became one of dementia, with masturbation and filthy habits, afterwards refusal of food, requiring forced alimentation, with delusions of grandeur resulting in chronic and hopeless insanity. (See "Cases.")

The Charrman considered that recovery seldom resulted when associated with habits of masturbation.

Dr. Merrick pointed out how recovery had followed in Dr. Patton's first case after a severe hæmorrhage, and that oftentimes improvement resulted from some severe shock to the system.

Dr. COURTENAY said that in many cases the recovery of the patient was often immediately after a severe outbreak of boils.

Dr. AsHe gave some details of a case of petit mal.

The ChaIRMAN drew attention to the religious habits of epileptics.

Dr. MoLONEY related an interesting case of a clergyman who took bromide of potassium as part of his daily food for a considerable time to wurd off epilepsy.

Dr. MERRICK stated that he only remembered one case of anæmic epilepsy in which recovery had taken place, that in the County Antrim a curious belief existed that pork was a cause of epilepsy, and that in his asylum the epileptics refused to eat pork.

Dr. CoURTENAY read a paper on "The Diet Tables of English Asylums."

The following were elected members of the Association :-

Myles, William Zachary, L.F.P.S.Gls., Asst. Med. Officer Richmond Asylum.

O'Neil, William Daniel, L.K.Q.C.P.I., Ass. Med. Officer Richmond Asylum.

Gordon, William Spear, M.B., Ass. Med. Officer, District Asylum Mullingar.

Harvey, Crosbie Bagnall, L.A.H.Dub., Asst. Med. Officer District Asylum, Clonmel.

\title{
“AFTER CARE."
}

\section{ADJOURNED MEETING, BETHLEM HOSPITAL, 29TH OCTOBER, 1885.}

Were present : Alfred J. Copeland, Esq., Treasurer of Bethlem Hospital, in the chair; Surgeon-General C. R. Francis, Dr. D. Hack Tuke, Dr. Norman Kerr, Dr. Cobbold (Earlswood Asylum), Dr. T. Clay Shaw, Hon. Treasurer of " After Care;" Rev. H. Hawkins, Hon. Secretary; Mrs. Ellis Cameron, Hon. Secretary Ladies' Committee; the Hon. Mrs. G. M. Glyn, Hon. Mrs. Pelham, Mrs. Pelham, and several other ladies.

The Hon. Szcremtary, in his report, referred to the death of the Earl of Shaftesbary, first President of the Association. Some incidents of his relation to it were referred to ; the expression of his interest in the subject of "After Care" when first brought under his notice; his acceptance of the Presidentship, and his presence as Chairman at four successive anniversaries ; his opinion of the need of "After Care," and of a home for mental convalescents. The result of a sale of fancy articles by Mrs. H. Hawkins was announced, for which a sum of $£ 192 \mathrm{~s} 6 \mathrm{~d}$ was forwarded to the treasurer's account at the Union Bank of London, Argyll Place.

Dr. SHaw read a statement of funds in hand or promised; referred to the boarding-out system adrocated by Dr. Lookhart Robertson as one way of find- 